\title{
Artigos
}

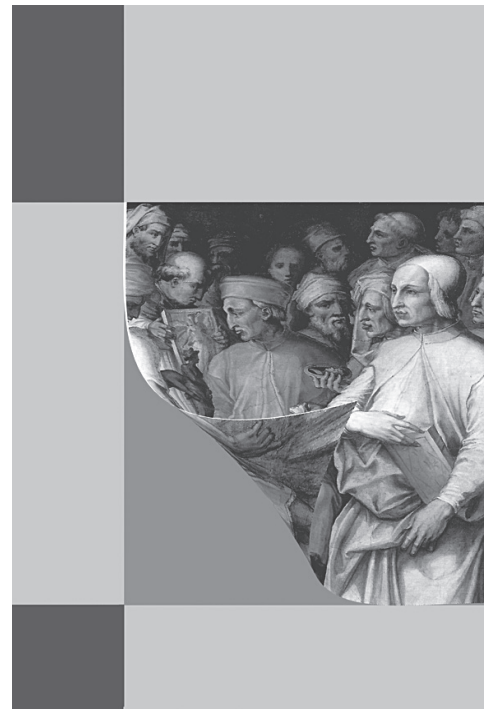




\title{
O DIREITO À EDUCAÇÃO E AS DINÂMICAS DE EXCLUSÃO NA AMÉRICA LATINA
}

\author{
PABlo Gentili*
}

\begin{abstract}
RESUMO: O presente artigo analisa o complexo processo de produção social da exclusão e seus efeitos no direito à educação. $\mathrm{O}$ autor descreve e interpreta três dinâmicas que interferem na realização desse direito nos países da América Latina e no Caribe: a pobreza e a desigualdade estruturais; a segmentação e a diferenciação dos sistemas nacionais de educação; e os sentidos que assume o direito à educação, numa cultura política marcada pelo desprezo aos direitos humanos e pela redução do valor da escolaridade aos efeitos que ela tem na concorrência pelos melhores postos no mercado de trabalho. O texto propóe redefinir a radicalidade do direito à educação como um direito humano fundamental, base para a construção de sociedades mais justas e igualitárias.
\end{abstract}

Palavras-chave: Direito à educação. Exclusão social e educação. Direitos humanos e educação. Política educacional na América Latina. Sistemas nacionais de educação.

The Right to education and eXClusion dynamics in Latin America

ABSTRACT: This paper analyses the complex process of the social production of exclusion and its effects on the right to education. The author describes and interprets three dynamics that

Este texto é parte de um estudo mais amplo com diversos desdobramentos, entre os quais um é a base do presente artigo: "Marchas y contramarchas. El derecho a la educación y las dinámicas de exclusión excluyentes en América Latina”, publicado na Revista Iberoamericana de Educación (Madri, n. 49, jan. 2009), da Organização dos Estados Ibero-Americanos (OEI).

** Doutor em Ciências da Educação, professor da Universidade do Estado do Rio de Janeiro (UERJ) e secretário executivo adjunto do Conselho Latino-Americano de Ciências Sociais (CLACSO).E-mail: pablo@lpp-uerj.net

Educ. Soc., Campinas, vol. 30, n. 109, p. 1059-1079, set./dez. 2009

Disponível em <http://www.cedes.unicamp.br> 
interfere in the enforcement of this right in Latin American and the Caribbean: structural poverty and inequity; sectorization and differentiation of the national systems of education; and the meaning of the right to education in a political culture that disdains human rights and reduces the value of schooling to its effects on the competition for the best positions in the labor market. The text aims to redefine the radicality of the right to education as a fundamental human right, as the bedrock on which fairer and more equal societies can be built.

Key words: Right to education. Social and educational exclusion. Human rights and education. Educational policy in Latin America. National educational systems.

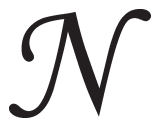

o dia 10 de dezembro de 1948, a Assembleia Geral das Nações Unidas proclamava a Declaração Universal dos Direitos $\mathrm{Hu}$ manos. A ONU havia sido constituída apenas três anos antes, e esta seria, talvez, uma de suas resoluçôes mais ambiciosas. Ela também se transformaria em um dos exemplos mais eloquentes de que, apesar dos avanços alcançados, as aspiraçôes igualitárias, que desde então fundamentaram acordos, declaraçôes e tratados internacionais sobre os direitos humanos, estão marcadas pela assimetria abismal que separa os princípios que os fundamentam das ações e práticas que deveriam consagrá-los. Assim, a Declaração que estabeleceu a universalidade dos direitos humanos com base em um contundente arsenal de valores e normas democráticas completa 60 anos, ao passo que no Norte assim como no Sul, nas sociedades chamadas "avançadas" assim como nas que aspiram a sê-lo, esses direitos desfrutam uma potência declarativa bem mais contundente que sua eficácia política para contribuir com a organização da vida dos povos, suas relações e conflitos.

Não há como negar que, parafraseando Paulo Sérgio Pinheiro, toda celebração de um tratado ou declaração pelos direitos humanos costuma ser um "exercício de frustração". De fato, diversas tendências têm caracterizado a história contemporânea da educação latino-americana, colocando em evidência os sérios limites que são e serão enfrentados pela possibilidade de consolidar e ampliar as fronteiras do direito à educação no sentido que a Declaração Universal dos Direitos Humanos já proclamava em 1948. A combinação de alguns fatores define aquilo que, em outros trabalhos, identificamos como um processo 
de escolarização marcado por uma dinâmica de exclusão includente; isto é, um processo mediante o qual os mecanismos de exclusão educacional se recriam e assumem novas fisionomias, no contexto de dinâmicas de inclusão e inserção institucional que acabam sendo insuficientes ou, em alguns casos, inócuas para reverter os processos de isolamento, marginalização e negação de direitos que estão envolvidos em todo processo de segregação social, dentro e fora das instituiçōes educacionais (Gentili, 1998; Gentili \& Alencar, 2001; Gentili, 2007). O conceito de exclusão includente pretende chamar a atenção sobre a necessidade de pensar o conjunto de dimensões que estão presentes em todo processo de discriminação, alertando para o fato de que, a partir desta multidimensionalidade, a necessária construção de processos sociais de inclusão (associados à realização efetiva dos direitos humanos e cidadãos e à consolidação de relaçôes igualitárias sobre as quais se constroem as bases institucionais e culturais de uma democracia substantiva) sempre depende de um conjunto de decisões políticas orientadas a reverter as múltiplas causas da exclusão, e não somente algumas delas, particularmente as mais visíveis.

Este último aspecto é fundamental, especialmente quando analisamos os processos de exclusão e inclusão no campo educacional. De fato, uma das dimensōes mediante a qual historicamente se produziu a negação do direito à educação dos mais pobres foi o não reconhecimento desse direito na legislação nacional, ou reconhecê-lo de forma fraca, indireta ou restrita, assim como o impedimento ao acesso de grandes setores da população aos níveis mais básicos da escolaridade, mesmo quando a legislação nacional assim o exigia. Excluídos de fato e de direito, os pobres viram suas oportunidades educacionais se diluírem em um arsenal de dispositivos e argumentaçôes mediante os quais se justifica sua baixa ou nula presença nos âmbitos educacionais. No início do século XXI, esta situação havia mudado de maneira notável. Hoje, "a probabilidade de que os meninos e as meninas com menos de 5 anos terminem seus estudos primários em 2015 é igual ou superior a 95\% na Argentina, Chile, Colômbia, Equador, México, Panamá, Peru e Uruguai, e se situa entre $90 \%$ e $95 \%$ no Brasil, Costa Rica e Venezuela" (UNICEF, 2006, p. 44). É no mínimo curioso o fato de que países que enfrentaram (ou ainda enfrentam) o rigor de políticas neoliberais de ajuste e privatização, principalmente durante os anos de 1990, tenham alcançado níveis de universalização nas oportunidades 
de acesso à educação básica iguais ou muito semelhantes aos de Cuba, cuja reforma educacional foi resultado de um processo revolucionário que já dura cinco décadas. Uma análise mais detalhada, contudo, revela que o problema é bem mais complexo, e é possível chegar a essa conclusão quando se estuda o conjunto de fatores que socialmente produzem a exclusão educacional nas sociedades latino-americanas. ${ }^{1}$

A análise da multidimensionalidade dos processos de exclusão no campo educacional nos permite observar os avanços e retrocessos percorridos na intenção de se superar os limites enfrentados pelas possibilidades de fazer do direito à educação uma oportunidade efetiva para as grandes maiorias. Por este motivo, é fundamental reconhecer que:

1) A exclusão é uma relação social, e não um estado ou posição ocupada na estrutura institucional de uma determinada sociedade. ${ }^{2}$ Dessa forma, os que estão excluídos do direito à educação não estão excluídos somente por permanecerem fora da escola, mas também por formarem parte de um conjunto de relações e circunstâncias que os afastam desse direito, negando ou atribuindo-lhes esse direito de forma restrita, condicionada ou subalternizada. Historicamente, negou-se aos pobres o direito à educação impedindo seu acesso à escola. Hoje, esse direito é negado quando não lhes é oferecida outra alternativa a não ser a de permanecer em um sistema educacional que não garante nem cria condiçõos para o acesso efetivo a uma educação de qualidade, quando se limitam as condições efetivas de exercício desse direito pela manutenção das condições de exclusão e desigualdade que se transferiram para o interior do próprio sistema escolar. Estas condições bloqueiam, travam e limitam a eficácia democrática do processo de expansão educacional, conduzindo os pobres para o interior de uma instituição que, em um passado próximo, dispunha de um conjunto de barreiras que limitavam suas oportunidades de acesso e permanência.

2) A inclusão é um processo democrático integral, que envolve a superação efetiva das condiçôes politicas, econômicas, sociais e culturais que historicamente produzem a exclusão. Por esse motivo, indicadores de melhorias nas condições de acesso a um direito, assim como todo avanço na luta contra a alienação, segregação ou negação de oportunidades, embora sempre suponham grandes 
conquistas populares, podem não ser suficientes para consagrar o fim dos processos de exclusão historicamente produzidos e que condicionam ou negam esse direito. É apressado, portanto, considerar que um direito está consagrado simplesmente pela superação parcial das condições que o negavam no passado. Em outras palavras, a inclusão educacional é um processo que se constrói em oposição às forças e tendências que produziram e historicamente produzem a negação do direito à educação dos mais pobres e excluídos. Afirmar que na América Latina houve um processo de inclusão educacional efetivo, sem analisar as particularidades que caracterizaram seu desenvolvimento, pode ser enganoso. A rigor, o que se observa durante a segunda metade do século xx é um importante processo de universalização do acesso à escola, associado a uma ampliação progressiva do reconhecimento legal sobre a obrigatoriedade escolar, cujo potencial democrático ainda depende de dotar estas experiências e oportunidades de certas condições políticas, revertendo tendências que, como as que indicaremos a seguir, limitam ou negam as possibilidades efetivas de afirmação desse direito. Quando se trata de um direito, não há, digamos assim, uma "inclusão pela metade". A soma de "partes" de um direito não garante a realização das condiçôes que lhe dão sentido e lhe atribuem necessidade histórica, embora o fato de ter avançado na conquista das posições e dos âmbitos que definem um direito sejam sempre uma necessidade e um imperativo democráticos. Não podemos deixar de reconhecer que avançamos de maneira notável na conquista do direito à educação na América Latina e no Caribe, embora esse avanço democrático dependa das possibilidades que tenhamos, no futuro, para mudar o sentido dos retrocessos que nos afastam ou questionam as condiçōes e oportunidades efetivas para fazer desse direito algo mais do que uma estatística que enfeita a propaganda governamental no momento de mostrar o cumprimento de metas e objetivos definidos para as próximas décadas, séculos ou milênios.

Neste artigo, pretendo mostrar que existem pelo menos três tendências orientadas a atacar e reverter os avanços alcançados, transformando a universalização das oportunidades de acesso à escola em uma "universalização sem direitos", e a expansão educacional da segunda 
metade do século passado em uma "expansão condicionada". Por "universalização sem direitos" entendo o processo de acesso à escola produzido em um contexto de deterioração das condições necessárias para que a permanência nesta permita tornar efetivas as dimensões atribuídas e reconhecidas ao direito à educação desde 1948. Afirmar que o processo de universalização da escola na América Latina não cumpre com os requisitos da Declaração Universal dos Direitos Humanos é algo bem mais grave que anunciar uma inconsistência jurídica bastante evidente no exercício de frustração que, como temos afirmado, supõem as efemérides de qualquer pacto ou tratado internacional de direitos humanos. Houve uma expansão da escolaridade, o que por suas implicações democráticas é uma notícia extraordinária, mas o direito à educação continua sendo negado a latino-americanos e latino-americanas, por meio da manutenção de fatores que impedem o desenvolvimento de suas plenas condiçōes de realização. Por "expansão condicionada" entendo o processo mediante o qual os sistemas nacionais de educação tenderam a crescer no contexto de uma intensa dinâmica de segmentação e diferenciação institucionais, que concede aos sujeitos que transitam pelos circuitos que constituem esses sistemas um status e um conjunto de oportunidades altamente desiguais.

Três dos fatores que contribuem para produzir a universalização sem direitos e a expansão condicionada dos sistemas educacionais latino-americanos são: a) a combinação e articulação de condições de pobreza e desigualdade vividas por um significativo número de pessoas em nossas sociedades; b) o desenvolvimento fragmentado dos sistemas escolares e os enormes diferenciais de oportunidades que as escolas oferecem; c) a promoção de uma cultura política sobre os direitos humanos - e particularmente sobre o direito à educação - marcada por uma concepção privatista e economicista que, longe de ampliar, restringe as fronteiras desse direito às oportunidades de acesso e permanência no mercado de trabalho. A exclusão includente no campo educacional produz-se não apenas, mas em parte, graças à combinação destes três fatores.

\section{Pobreza e desigualdade}

A expansão da cobertura educacional na América Latina permitiu que setores tradicionalmente excluídos do sistema escolar tivessem acesso a ele. Contudo, os altos níveis de pobreza e exclusão, associados 
à persistente desigualdade e à injustiça social que caracterizam o desenvolvimento latino-americano contemporâneo, formaram uma combinação que limitou o potencial democratizante desta expansão. Os altos níveis de miséria associados à fome, à desnutrição e às péssimas condiçôes de vida e de saúde da população mais pobre conspiram contra a possibilidade de que o trânsito pelas instituições escolares seja a oportunidade real de democratização de um direito humano. ${ }^{3}$ Atualmente existem mais de 180 milhôes de pobres na América Latina, e embora tenha havido uma tendência à diminuição dos índices de pobreza, tudo indica que a crise e a recessão econômica mundiais, que exercem um intenso impacto sobre a região, produzirão um aumento desses indicadores como consequência da precarização das condições de vida de boa parte da população. ${ }^{4}$ Essa precarização, sem dúvida alguma, estará associada à crise do mercado de trabalho, já visível em quase todos os países, ao intenso aumento do desemprego e, consequentemente, à redução da renda da população mais pobre, já que, como se sabe, este setor tem sua fonte de renda fundamentalmente no mercado de trabalho formal e informal, motivo pelo qual qualquer retrocesso neste campo produz como consequência uma crise nas condições de vida da população. Os anos de 1980 e de 1990 constituíram um período de intensificação dos índices de pobreza e indigência, situação que começou a ser revertida nos últimos anos de maneira tênue, embora progressiva. ${ }^{5}$ Tudo parece indicar que a recessão e a instabilidade que explodiram nos mercados por volta do final de 2008 pré-anunciam uma regressão nos índices de pobreza e indigência para os próximos anos.

A situação herdada e as perspectivas futuras são particularmente graves diante do fato de que, em nossos países, a pobreza tem um impacto bem mais contundente sobre a população infantil e juvenil que sobre a população adulta. Ou seja, a intensificação ou a manutenção dos altos índices de pobreza e indigência tendem a condicionar seriamente as oportunidades de vida e os direitos da população com menos de 18 anos. Em todos os países da América Latina, a incidência da pobreza é maior ou significativamente maior entre meninos, meninas e jovens que entre o restante da população (CEPAL, 2008). ${ }^{6}$ Dessa forma, toda situação de pobreza estrutural ou de intensificação desta, inevitavelmente, exercerá impacto sobre o sistema escolar, questionando, interferindo e fragilizando as condições para o exercício do direito à educação. Desde a primeira infância até a adolescência, as condições de 
pobreza e indigência interferem de maneira intensa nas oportunidades educacionais dos mais pobres. O ciclo que vai do nascimento ao prematuro ingresso no mercado de trabalho, também acompanhado, no caso das meninas, pelo exercício prematuro de uma maternidade marcada por riscos e por uma assistência médica precária, condiciona seriamente as oportunidades educacionais da infância latino-americana e caribenha, questionando seu direito à própria vida. $\mathrm{O}$ último relatório do UNICEF (2008b), Progresso para a infância - um balanço da mortalidade materna, evidencia como as taxas de mortalidade infantil e o risco de morrer por causas relacionadas à maternidade são, na América Latina, imensamente mais altos entre os setores mais pobres da população, particularmente em alguns países como Haiti, Bolívia, Honduras e Peru. Neste sentido, "as desigualdades econômicas reduziram o avanço dos progressos em direção à educação universal, pois o risco de abandonar a escola é maior nos estratos sociais mais baixos" (UNICEF, 2006, p. 46).

As consequências da pobreza não são particularmente graves apenas entre a população infantil e juvenil, mas também exercem um impacto especial sobre a população indígena e afro-latina. Ambas as dimensōes, logicamente, combinam-se de forma inevitável. Grande parte da população indígena e negra, um pouco mais de 200 milhões de latino-americanos e latino-americanas, são pobres e indigentes e, entre os pobres e indigentes, os que sofrem esta condição de forma mais intensa são os negros e os indígenas. Ao mesmo tempo, a maioria dos pobres e indigentes, considerando o total deles, é de crianças e jovens, assim como a metade dos afro-latinos e dos indígenas é também de meninos, meninas e jovens. As condições de pobreza e indigência aumentam significativamente para a população entre 0 e 18 anos e para a população indígena ou negra. Nestes termos, a maior probabilidade de ser pobre na América Latina ou no Caribe é ser indígena ou afrolatino e ter menos de 18 anos. Nos países com altos índices desta população, como Brasil, Colômbia, Peru, Equador, Bolívia, México e Paraguai, os níveis de pobreza e indigência da população indígena ou afro-latina chegam, em alguns casos, a se duplicar em relação aos níveis de pobreza e indigência entre a população não indígena ou negra, ao passo que esses níveis chegam a aumentar notoriamente quando se trata de meninos e meninas. Portanto, não se trata de um exercício de "cartomancia sociológica" reconhecer que as oportunidades educacionais 
de meninos, meninas e jovens indígenas e afro-latinos são bem mais limitadas que as de meninos, meninas e jovens em geral, e que as do restante dos pobres em particular. A maior probabilidade de estar excluído da escola ou de ter acesso a uma escolaridade profundamente degradada em suas condições de desenvolvimento pedagógico é ter nascido negro, negra ou indígena, em qualquer país da América Latina ou do Caribe. ${ }^{7}$

A afirmação anterior articula-se a um aspecto relacionado à pobreza, embora de especificidade própria: a desigualdade. A distribuição da renda na América Latina é a mais injusta de todo o planeta. $\mathrm{Na}$ região, mesmo quando a pobreza diminui, os níveis de desigualdade mantêm-se inalterados ou baixam mais lentamente que os níveis de miséria e indigência. Em outras palavras, ainda que algumas sociedades consigam reduzir a pobreza, a injustiça social permanece, por décadas, de forma constante, especialmente quando comparamos a apropriação dos benefícios econômicos pela parcela dos $10 \%$ mais ricos da sociedade e o que corresponde aos $40 \%$ mais pobres.

Este panorama de desigualdades possui diversos aspectos no campo educacional e permite a compreensão das dimensões do idiossincrático processo de universalização do acesso à escola, mas sem direito à educação, que se desenvolveu na América Latina durante as últimas décadas. De maneira geral, na região, houve uma enorme correspondência entre a pobreza em termos sociais e a pobreza em termos educacionais, situação que tendeu a se aprofundar à medida que os pobres conseguiam superar mais e mais barreiras de acesso e permanência dentro do sistema educacional. É significativo associar esta observação a um fenômeno não menos antidemocrático existente em nossos países: a persistente desigualdade social articula-se a uma também persistente e cada vez mais complexa desigualdade educacional. Dessa forma, a escola universaliza-se, mas o faz em condiçóes de extrema pobreza para aqueles setores que agora sim conseguiram ingressar nela, multiplicando as desigualdades e polarizando ainda mais as oportunidades educacionais dos $10 \%$ mais ricos em relação aos $40 \%$ mais pobres. Um sistema educacional pobre e desigual é o correspondente eloquente de sociedades que avançam sustentadas em um modelo de desenvolvimento que gera um enorme número de pobres e uma brutal e estrutural desigualdade. É esta combinação de pobreza e desigualdade que hipoteca o direito à educação das grandes maiorias, transformando as cada vez mais amplas 
oportunidades educacionais das minorias em um verdadeiro privilégio. A desigualdade no campo educacional faz com que, na medida em que as oportunidades dos mais pobres aumentam (embora isso aconteça em condiçôes também de extrema pobreza), também tendam a aumentar as condiçōes e as oportunidades de educação dos mais ricos. Os pobres hoje passam mais anos no sistema escolar. Os ricos também, e, ao fazêlo em melhores condições e também com um progressivo aumento de suas oportunidades e alternativas educacionais, a desigualdade educacional, longe de diminuir, aumenta ou mantém-se constante. ${ }^{8}$

$\mathrm{O}$ tratamento desigual em relação às oportunidades educacionais, associado ao tratamento desigual em relação a todas as oportunidades sociais, torna-se muito mais severo naqueles grupos da população que, como os indígenas e os afro-latinos, sofrem de maneira mais intensa a discriminação e a exclusão. Uma das evidências mais eloquentes e perversas da desigualdade educacional na América Latina é a persistência do racismo dentro do sistema escolar, o lado obscuro de sociedades que se condecoram como sendo as herdeiras de uma mestiçagem providencial e devotas de uma suposta democracia racial que a realidade se esforça dia a dia para desmentir. $\mathrm{O}$ racismo educacional persiste na América Latina mediante processos de discriminação pedagógica e curricular, como evidenciaram diversos estudos e pesquisas, assim como em uma constante e tenaz segregação sofrida por esses grupos na qualidade e na quantidade de suas oportunidades educacionais.? As oportunidades de acesso e permanência da população indígena e negra aumentaram substantivamente na América Latina. Contudo, a distância que separa as condiçôes educacionais entre esses grupos e os mais favorecidos não diminuiu, e a produção institucional do apartheid educacional tornou-se mais complexa, embora menos contundente.

\section{Segmentação e diferenciação dos sistemas escolares}

Os processos de universalização das oportunidades de acesso à educação viram-se interferidos por intensos processos de diferenciação e segmentação dos sistemas escolares, assinalados com grande regularidade nos estudos regionais sobre esta matéria. Os sistemas nacionais de educação na América Latina encontram-se altamente diferenciados em circuitos institucionais que concentram condições e oportunidades educacionais altamente heterogêneas e profundamente desiguais. Um 
processo que, já nas pesquisas do célebre projeto "Desenvolvimento e Educação na América Latina e no Caribe", promovido pela UNESCO, pela CEPAL e pelo PNUD por volta do final dos anos de 1970 e início dos de 1980, havia sido identificado com pertinente profundidade analítica. A rigor, a própria definição de "sistema educacional" choca-se com a realidade de aparelhos institucionais altamente heterogêneos em suas dinâmicas de funcionamento, em suas condiçôes de acesso a recursos, no perfil dos docentes que neles atuam, no tipo de alunos e alunas que convocam, assim como no tipo e na qualidade dos conhecimentos que ministram. O ideal de uma escolaridade comum tem sido conquistado no espaço formal de uma legislação que amplia e certamente ampliará o reconhecimento jurídico do direito à educação de todos, sem nenhum tipo de discriminação ou exclusão. Contudo, esta aspiração tropeça em um aparelho institucional que, embora aberto a todos, acolhe os sujeitos de forma desigual em função de certos atributos que os princípios democráticos condenam, pelo menos eticamente: a cor da pele, seu grupo étnico de origem, o gênero, a região ou o bairro onde moram, a profissão do pai e da mãe, seus salários (ou a falta deles), etc. Nestes termos, a escola universalizou-se sem ampliar ou democratizar sua condição "pública", isto é, sem que se tenha ampliado seu status de bem comum, de direito social desmercantilizado e atravessado por uma radical aspiração a melhorar de forma permanente a socialização de seus benefícios. Hoje existem mais oportunidades de acesso à escola do que 60 anos atrás, quando foi proclamada a Declaração Universal dos Direitos Humanos, mas também se tornaram mais complexas e difusas as formas de exclusão educacional e a negação das oportunidades escolares daqueles que, estando dentro do sistema, continuam com seu direito à educação negado.

As oportunidades educacionais tornam-se mais desiguais em um sistema escolar institucionalmente mais complexo e heterogêneo, menos igualitário e mais polarizado, segmentado e diferenciado, formado por uma teia de aranha de circuitos nos quais os bens educacionais, longe de se constituir em sua condição de direitos iguais e inalienáveis, cristalizam-se em sua condição de mercadorias vendidas ou compradas, concedidas pela graça governamental ou negadas pela petulância e pela prepotência de uma elite que aumenta seu poder sobre a base de uma ficção doutrinária: a aparente consistência entre o reconhecimento formal dos direitos e o tratamento desigual que o mercado concede aos 
diferentes seres humanos, em virtude de suas também desiguais oportunidades a certos bens e recursos. Em outras palavras, a suposta coerência entre a afirmação da igualdade diante da lei e a brutal desigualdade de condiçóes de vida que cada um de nós enfrenta para usufruir as oportunidades que o mercado oferece.

O direito à educação torna-se assim a quimera de um sistema que consagra a distribuição desigual dos benefícios educacionais como o resultado natural de um mercado que premia e castiga os indivíduos em virtude de seus supostos méritos cognitivos e de suas vantagens econômicas herdadas ou adquiridas. Uma quimera que adquire o rosto de uma bela sereia ou de um monstro petulante, de acordo com o lugar a partir do qual tenhamos a sorte ou a desgraça de observá-la. $\mathrm{Na}$ América Latina, todos têm formalmente o mesmo direito à educação e a todos, sem distinção, esse direito tem estendido seus braços e generosamente alargado suas fronteiras. O problema parece estar no fato de que, para fazer desse direito uma oportunidade efetiva, é necessário introduzir-se em um aparelho institucional que teria deixado pasmo até o próprio Josef $\mathrm{K}$, protagonista do célebre relato de Franz Kafta, $O$ processo: um labirinto de intermináveis vielas, onde somente os eleitos conhecem o caminho da saída, ao passo que os pecadores (negros, indígenas, pobres, imigrantes, camponeses, jovens, trabalhadores, desempregados, mulheres, crianças, esfomeados e famintos por comida e justiça social) embarcam no caminho de uma trajetória pedagógica marcada por um fracasso anunciado aos que aspiram apenas a contrariar a sorte.

Sistemas educacionais divididos em sociedades divididas - essa parece ser a fisionomia de uma estrutura escolar que se expande condicionando as oportunidades e distribuindo bens simbólicos de uma forma tão desigual quanto são distribuídos os bens econômicos. Não há dúvidas de que nas sociedades contemporâneas há mais riquezas e bens acumulados. Tampouco há dúvidas de que nas sociedades contemporâneas há mais conhecimentos socialmente disponíveis. Nosso direito à educação deveria tornar esses conhecimentos um bem de todos. Contudo, o sistema escolar, partido e dividido, longe de democratizar seu acesso, conduz os sujeitos pelos circuitos que melhor se adaptam às marcas ou aos estigmas que definem o tamanho de seus direitos e oportunidades. Todos têm o mesmo direito à educação, mas nem todos exercem da mesma forma seu direito à escola, motivo pelo qual os resultados do processo de escolarização são tão desiguais como 
são desiguais as condições de vida de grupos, classes, estratos ou castas que compóem a sociedade ou, em termos mais precisos, o mercado.

As condições observacionais deste processo são bem conhecidas e estudadas na América Latina. ${ }^{10}$ Já mencionamos algumas delas, e outras, não menos importantes, têm sido motivo de diversas pesquisas:

a) Acesso e progressão educacional diferenciada.

b) Discriminação pedagógica e conquistas escolares desiguais em virtude de critérios de gênero, desigualdades regionais, raciais e étnicas.

c) Herdabilidade das oportunidades educacionais.

d) Qualidade educacional desigual.

e) Injustiça curricular.

f) Distribuição desigual das oportunidades educacionais: docentes diferentes, escolas diferentes, recursos pedagógicos diferentes, "concorrências" diferentes, aprendizagens diferentes, expectativas educacionais diferentes, sucessos e fracassos diferentes.

A expansão condicionada dos sistemas nacionais de educação, na América Latina, expressa, talvez, o resultado de uma troca perversa, cujas raízes estão ancoradas em sociedades profundamente antidemocráticas: os poderosos parecem ter aceitado que as massas deveriam ter direito à educação, desde que o sistema educacional se enfraquecesse como a instituição em cuja permanência esse direito se garante. Além de permanecer, para ter direito à educação é preciso "pertencer", já que, como diz a propaganda de um exclusivo cartão de crédito, "pertencer tem seus privilégios"...

\section{Sentidos do direito à educação}

Tal como afirmamos no início deste artigo, a Declaração Universal dos Direitos Humanos foi provavelmente uma das declarações mais poderosas e ambiciosas na luta pela igualdade e pela justiça social. Já se passaram 60 anos desde que a inclusão da educação como um direito humano fundamental supôs o reconhecimento de uma série de questões associadas e indissoluvelmente unidas a esse direito, todas elas com 
um enorme potencial democratizante e inspiradas em uma concepção libertária e emancipadora da justiça social. Neste sentido, mais além dos componentes que definem o direito à educação no artigo $26 \mathrm{da}$ Declaração, é significativo observar que, transversalmente, o conjunto de direitos que formam a declaração de 1948 estão fundamentados e ganham relevância na medida em que o direito à educação se torna uma realidade efetiva. Reconhece-se nesta Declaração, sem sombra de dúvidas, um prometeico e esperançoso espírito iluminista. Uma confiança na Razão e no entendimento humano sobre a qual, hoje, com fundamentados motivos, poderíamos colocar um ponto de interrogação. $\mathrm{O}$ fato incontestável é que a afirmação do direito à educação como um direito humano fundamental estava associada ao reconhecimento das condições indispensáveis para a construção de uma sociedade mais justa e igualitária.

Não disponho de espaço suficiente para apresentar cada artigo da Declaração Universal dos Direitos Humanos, analisando suas claras implicações e formas de articulação com a promoção do direito à educação, embora uma rápida leitura desses artigos nos permitisse constatar que a relevância democrática da educação reside, do ponto de vista dos direitos humanos, em que tal educação constitui um bem que abre, constrói, potencializa e afirma outros direitos. A Declaração de 1948 reconhecerá que a educação é um direito humano, um bem público e social, porque ela nos ajuda a nos comportarmos e a nos reconhecermos como seres humanos livres e iguais em direitos, a nos tratarmos de maneira fraternal, a lutar contra toda forma de escravidão e servidão, contra toda forma de discriminação, tortura e tormento, de aspiração colonial ou imperial; a educação protege-nos e é a defesa de nossa identidade, de nossa privacidade e de nossa honra, de nossa liberdade e da liberdade de todos, da dignidade, da felicidade (ela mesma, um bem comum), de toda liberdade de pensamento, do bem-estar, do acesso à riqueza acumulada, à saúde, à vivência plena de nossa sexualidade, nossa cultura e nossa moralidade. A educação é um direito humano fundamental porque é a base, o início e, ao mesmo tempo, a aspiração e o ponto de chegada de toda luta pela justiça social e pela igualdade, de toda luta contra a humilhação e o desprezo aos quais são submetidos milhões de seres humanos por terem nascido pobres (Gentili, 2007). Assim, pelo menos, parecia prefigurar-se nos princípios que guiaram a célebre Declaração de 1948. 
Não deve ser motivo de alegria que, 60 anos depois, isso soe de forma tão ridícula quanto utópica, atributo que se confere a toda aspiração inalcançável e supostamente enganosa na vida das pessoas e dos povos.

Uma das causas que talvez explique este processo não reside tanto na desmedida ambição daqueles que formularam a sessentona e ainda pouco estreada Declaração, mas sim no fato de que, durante a última metade do século XX até nossos dias, a educação foi submetida a uma dura disputa sobre os motivos que a fundamentam e a dotam de sentido. De fato, foi justamente em meados dos anos de 1940 que os estudos sobre os efeitos econômicos da educação começaram a se desenvolver, particularmente sob a direção de Theodore Schultz, como diretor da Escola de Economia da Universidade de Chicago, cargo que exerceu desde 1946. O enfoque que tendeu a atribuir à educação um valor econômico fundamental no desenvolvimento esteve amparado em um arsenal de pesquisas empíricas que renderam pelo menos três Prêmios Nobel: Milton Friedman (1976), o próprio Theodore Schultz (1979) e Gary Becker (1992). Este último, o mais célebre formulador da Teoria do Capital Humano, cujo poder normativo e pré-formativo dos discursos políticos sobre a educação foi esmagador antes, durante e, tragicamente, depois das administraçôes neoliberais. A partir desta perspectiva, a educação é um fator de produção que permite ampliar as oportunidades de ingresso e a competitividade dos agentes econômicos no mercado. Assim, os portadores dos bens educacionais aumentam seus lucros na medida em que, fazendo um uso racional desses bens, desenvolvem estratégias competitivas que lhes permitem maximizar seus benefícios em um mercado cada vez mais seletivo. A educação aumenta a produtividade e as oportunidades educacionais aumentam as possibilidades de competir pelo domínio dos conhecimentos técnicos e disciplinares necessários para competir no mercado, ocupando as melhores posições e apropriando-se dos mais disputados benefícios.

Mais além e em contraposição à perspectiva humanista da Declaração de 1948, desde a segunda metade do século XX este tem sido o argumento utilizado com espantosa regularidade por gregos e troianos para explicar por que a educação está em crise, assim como para explicar também por quê, uma vez superada tal crise, a educação poderia nos conduzir pelo caminho da felicidade e do bem-estar geral. A relação linear e inequívoca estabelecida entre educação e desenvolvimento 
econômico, associada à também supostamente inequívoca relação entre educação e emprego, ou educação e aumento da renda individual e social, não apenas entrava em contradição com os princípios éticos que dotavam de sentido a educação como direito humano, como também, fundamentalmente, foi utilizada como o argumento que condenava ao sótão da história toda associação entre educação e cidadania, educação e política, educação e igualdade. A partir deste ponto de vista, o raciocínio sempre foi bastante simples e contundente: quanto mais educação, mais desenvolvimento; quanto mais educação, melhores empregos; quanto maior for o aumento dos bens educacionais, consequentemente maior será o aumento da renda pessoal. E tantas outras afirmações equivocadas. Dessa forma, se a educação "funciona" bem, a sociedade também o faz (pressupondo que as sociedades funcionam melhor quando a riqueza acumulada aumenta). Se a educação "funciona" mal, também funciona mal a sociedade e, em um contexto de pobreza, o desenvolvimento transforma-se em uma aspiração distante e tênue. Seria uma afirmação bonita, se não fosse parcialmente falsa e enganosa.

Enquanto a Declaração de 1948 reafirmava a dimensão pública da educação e seu poder capaz de instituir uma nova sociedade baseada nos princípios do reconhecimento, da igualdade e da justiça social, o economicismo educacional ia impregnando e contaminando os discursos de sociedades e governos, para os quais o sentido da educação se afirma nas vantagens econômicas que esta pode produzir. É notável que na declaração da ONU não houvesse nenhuma referência direta a argumentos que justificassem o valor da educação a partir de sua contribuição para a produção de riquezas. Contudo, foi esta a concepção que tendeu a se impor, contra a interpretação política, tendencialmente igualitária e radicalmente democrática, que encerrou, há 60 anos, o reconhecimento da educação como direito humano fundamental. Uma concepção democratizante, pública e inerentemente igualitária, política e sustentada na doutrina dos direitos humanos, ao mesmo tempo em que, ela mesma, sustenta toda compreensão crítica sobre a vocação sempre desestabilizadora da educação como direito que constrói e amplia outros direitos. Uma concepção socializante versus uma concepção privatizadora, plataforma a partir da qual é possível construir os princípios e as práticas de uma educação libertadora. Uma concepção socializante versus uma interpretação mercantilizada dos bens educacionais. Uma concepção tragicamente derrotada versus uma concepção tragicamente vencedora. 
Atribuir como principal mérito da educação suas virtudes para ampliar os retornos econômicos do investimento educacional tem suposto nestes últimos 60 anos enfatizar os benefícios privados por ela gerados e, consequentemente, reduzir o papel do Estado a uma função subsidiária periférica ou meramente assistencial. A Declaração de 1948 abre, porém, uma dimensão diferente para o papel da educação e o papel do Estado em toda sociedade democrática. Por um lado, atribui a ela a condição de direito coletivo que, ainda deixando margem para a liberdade da escolha individual, tem no Estado seu principal responsável e garantidor. Por outro, afirma o direito inalienável dos indivíduos de se defenderem do Estado quando este não cumpre com suas funções, exigindo pela força do direito violado a restituição desta garantia e de seus benefícios. A educação é assim um direito de todos e a violação desse direito a um único indivíduo supõe o questionamento de tal direito a todos os indivíduos. A partir de uma perspectiva democrática, não há inclusão social que possa ser parcial, sendo esta mais que a soma dos fragmentos de espaços inconclusos nos quais se conquista um pedaço da promessa integradora. Um princípio semelhante aplica-se aos direitos humanos. Não há direitos pela metade e não é consistente a ideia de que os direitos coletivos estão garantidos quando boa parte dos indivíduos se beneficia destes. Em outras palavras, não há princípio de maioria que se aplique aos direitos humanos: não é porque um grande número de pessoas possui "direito à educação" que o direito à educação é um direito coletivo. $\mathrm{O}$ direito à educação, como direito humano fundamental, ou pertence a todos ou não pertence a ninguém. $\mathrm{E}$, se não pertence a ninguém, o princípio democrático sobre o qual se deve sustentar todo projeto de sociedade igualitária e emancipada de poderes arbitrários e totalitários se enfraquece ou desaparece. Isso é o que diferencia o valor público e político da educação como direito de todos, contra o princípio mercantilizador e privatizador da educação como um direito individual, que somente adquire relevância na medida em que é capaz de criar valores no mercado.

A luta pelos sentidos da educação e, indissoluvelmente, a controvérsia pelos sentidos do direito que deve garanti-la fazem parte de uma luta mais ampla pelo modelo de sociedade que queremos, imaginamos e aspiramos a construir. $\mathrm{O}$ futuro do direito à educação e a luta contra a exclusão refletem-se no mesmo horizonte. Um horizonte no qual a conquista da justiça social e a igualdade educacional deverão sustentar os 


\section{pilares de um projeto de emancipação e de liberdade para nosso con- tinente.}

\section{Recebido e aprovado em outubro de 2009.}

\section{Notas}

1. Ver a esse respeito os diversos estudos sobre o direito à educação na América Latina promovidos pelo Fórum Latino-Americano de Políticas Educacionais (FLAPE): www.foro-latino.org

2. Duas importantes compilações que contribuem para uma compreensão dialética dos processos de exclusão podem ser encontradas em Karsz (2004) e Paugan (1996).

3. Sobre os efeitos da fome na aprendizagem, ver o relevante estudo do Programa Mundial de Alimentos das Nações Unidas (2006). Também, sobre o impacto que as péssimas condiçōes de saúde e as fracas políticas públicas do setor geram na população infantil e juvenil mais pobre, ver o último Relatório sobre a Saúde no Mundo (oms, 2008), dedicado aos primeiros atendimentos na saúde.

4. Embora tenha diminuído em termos relativos, o número de pobres aumentou em termos quantitativos em relação a 1980, quando estes chegavam a 140 milhões de habitantes em toda a região.

5. Em alguns países, a redução dos níveis de pobreza e indigência foi muito significativa. Entre 2002 e 2006, por exemplo, a Argentina reduziu seus índices de pobreza em 18\% e de indigência em 22\%. Na Venezuela, entre 2002 e 2007, a redução foi de $12 \%$ e 17\%, respectivamente. Em quase todos os países, com exceção do Uruguai, onde a pobreza cresceu $3 \%$ e a indigência $4 \%$ entre 2002 e 2007 , a diminuição desses índices foi superior a $5 \%$ (CEPAL, 2008).

6. Em países como Uruguai, Argentina, Venezuela, Panamá, Brasil, México, Equador, Colômbia, El Salvador, Bolívia, Chile, Guatemala, Paraguai, Nicarágua e Honduras, os índices de pobreza entre a população de 0 a 18 anos chegam a ser quase o dobro que o da população com 19 a 64 anos (CEPAL, 2008).

7. No Brasil, por exemplo, a taxa de alfabetização para a população branca urbana com mais de 25 anos é de $93,7 \%$, ao passo que a da população negra é de $85,7 \%$. No meio rural, os brancos com mais de 25 anos possuem uma taxa de alfabetização de $79,5 \%$ e os negros, de $62,2 \%$. A média de anos de estudo no meio urbano para a população branca é de 8,1 , ao passo que a da população negra é de 6,2 ; no âmbito rural, as taxas são de 4,3 e 2,9 , respectivamente. No Equador, a taxa de analfabetismo da população branca é de $4,7 \%$, dos afro-equatorianos é de $10,3 \%$ e dos indígenas é de $28,1 \%$ (Paixão \& Carvano, 2008). Na Colômbia, de acordo com dados do Censo Geral de 2005, o índice de analfabetismo entre a população negra é de $10,92 \%$ e entre a população não negra é de $6,91 \%$. Nos Departamentos de Nariño e Choco a diferença é ainda maior: 22,23\% - 9,24\% e $18,24 \%$ - 12,74\%, respectivamente (Observatório da Discriminação Racial: http:// odr.uniandes.edu.co/pdfs/Cifras/Analfabetismo.pdf). Na Bolívia, a população indígena possui quase 4 anos a menos de escolaridade (5,9 anos) que a não indígena (9,6 anos). Um terço das crianças indígenas bolivianas entre 9 e 11 anos trabalha, proporção quatro vezes superior à das crianças não indígenas. Os guatemaltecos indígenas entre 15 e 31 anos apresentam uma média de 3,5 anos de escolaridade, ao passo que os não indígenas 
apresentam uma média de 6,3 anos. Apenas a metade da população indígena da Guatemala sabe ler e escrever, ao passo que pouco mais de $82 \%$ da população não indígena o faz. Quase $45 \%$ da população indígena guatemalteca abandona o primeiro ano de seu processo de escolarização. No México, a população indígena adulta possui menos de 4,6 anos, ao passo que entre a população não indígena esse índice é de 7,9. Um quarto da população indígena é analfabeta, ao passo que $6,4 \%$ dos não indígenas o são. No caso das mulheres indígenas, essa diferença é ainda maior: elas possuem quase 5 anos a menos de escolaridade que as mulheres não indígenas (Hall \& Patrinos, 2006).

8. Em nossos países é comum estudar muito mais a produção social da pobreza que a da riqueza. Dessa forma, costumam também ser muito mais frequentes estudos sobre as condições da educação dos excluídos que estudos os quais abordam as formas e oportunidades educacionais dos mais ricos. A ausência de estudos sobre a produção social da riqueza e da educação é um sério limite para uma análise rigorosa da exclusão educacional, à qual está associada. Não é possível compreender a produção social da miséria sem que se entendam os mecanismos de produção social da riqueza, aspectos que, no campo educacional, adquirem particular relevância. Uma exceção a esta observação pode ser encontrada nas pesquisas de Tiramonti e Ziegler (2008) e nas de Almeida e Nogueira (2002).

9. Diversos estudos sobre os processos de discriminação racial no campo educacional podem ser encontrados no centro de documentação do Observatório Latino-Americano de Políticas Educacionais, do Laboratório de Políticas Públicas OLPED/LPP: www.olped.net

10. Importantes contribuições nesta direção podem ser encontradas em Tedesco (2005), Azevedo (2008) e Tenti (2008).

\section{Referências}

ALMEIDA, A.M.; NOGUEIRA, M.A. (Org.). A escolarização das elites: um panorama internacional de pesquisa. Petrópolis: Vozes, 2002.

APONTE-HERNÁNDEZ, E. Desigualdad, inclusión y equidad en la educación superior en América Latina y el Caribe: tendencias y escenarios alternativos en el horizonte 2021. In: GazzolA, A.L.; Didriksson, A. (Ed.). Tendencias de la educación superior en América Latina y el Caribe. Caracas: UNESCO/IESALC, 2008.

AZEVEDO, M.L.N. (Org.). Politicas públicas e educação: debates contemporâneos. Maringá: EDUEM, 2008.

BOBBIO, N. Teoria geral da política: a filosofia política e as liçôes dos clássicos. Rio de Janeiro: Campus, 2000.

BOLIVIA. Ministerio de Educación y Culturas. Politicas de descolonización de las prácticas educativas. La Paz, 2007.

Educ. Soc., Campinas, vol. 30, n. 109, p. 1059-1079, set./dez. 2009

Disponível em <http://www.cedes.unicamp.br> 
COMISIÓN ECONÓMICA PARA AMÉRICA LATINA Y EL CARIBE (CEPAL). Panorama Social de América Latina 2007. Santiago de Chile, 2007.

COMISIÓN ECONÓMICA PARA AMÉRICA LATINA Y EL CARIBE (CEPAL). Panorama Social de América Latina 2008. Santiago de Chile, 2008.

CONNELL, R. Escuelas y justicia social. Madrid: Morata, 1997.

GENTILI, P. A falsificação do consenso: simulacro e imposição na reforma educacional do neoliberalismo. Petrópolis: Vozes, 1998.

GENTILI, P. Desencanto y utopía: la educación en el laberinto de los nuevos tiempos. Rosario: Homo Sapiens, 2007.

GENTILI, P.; ALENCAR, C. Educar na esperança em tempos de desencanto. Petrópolis: Vozes, 2001.

HALL, G.; PATRINOS, H.A. Pueblos indigenas, pobreza y desarrollo humano en América Latina: 1994-2004. Bogotá: Banco Mundial; Mayol, 2006.

KARSZ, S. (Coord.). La exclusión: bordeando sus fronteras; definiciones y matices. Barcelona: Gedisa, 2004.

LANDER, E. (Ed.). La colonialidad del saber: eurocentrismo y ciencias sociales; perspectivas latinoamericanas. Buenos Aires: CLACSO, 1993.

LÓPEZ, N. Las nuevas leyes de educación en América Latina: una lectura a la luz del panorama social y educativo de la región. Buenos Aires: ClADE/IIPE; UNESCO, 2007.

MUÑOZ, V. (Ed.). El oro por las cuentas: miradas a la mercantilización de la educación. San José: Luna Híbrida, 2006.

NASSIF, R.; RAMA, G.; TEDESCO, J.C. El sistema educativo en América Latina. Buenos Aires: Kapeluz; UnESCO/CEPAL/PNUd, 1984.

ORGANIZACIÓN MUNDIAL DE LA SALUD (OMS). Informe sobre la salud en el mundo 2007: un porvenir más seguro; protección de la salud pública mundial en el siglo XXI. Genebra, 2008. 
PAIXÃO, M.; CARVANO, L.M. Relatório anual das desigualdades raciais no Brasil 2007-2008. Rio de Janeiro: Garamond, 2008.

PAUGAN, S. (Ed.). L'exclusion: l'état des savoirs. Paris: La Découverte, 1996.

ORGANIZACIÓN DE LAS NACIONES UNIDAS (ONU). Programa Mundial de Alimentos. Serie de informes sobre el hambre en el mundo 2006: el hambre y el aprendizaje. Roma, 2006.

SADER, E. A nova toupeira: os caminhos da esquerda latino-americana. São Paulo: Boitempo, 2009.

TEDESCO, J.C. (Comp.). ¿Cómo superar la desigualdad y la fragmentación del sistema educativo argentino? Buenos Aires: IIPE, 2005.

TENTI, E. (Comp.). Nuevos temas en la agenda de política educativa. Buenos Aires: Siglo XXI, 2008.

THERBORN, G. (Ed.). Inequalities of the world: new theoretical frameworks, multiple empirical approaches. London: Verso, 2006.

TIRAMONTI, G.; ZIEGLER, S. La educación de las elites: aspiraciones, estrategias y oportunidades. Buenos Aires: Paidós, 2008.

TOMASEVSKI. K. El asalto a la educación. Barcelona: Intermón Oxfam, 2004.

UNICEF. Logros y perspectivas en materia de género en educación; informe GAP, primera parte. Nova York, 2006.

UNITED NATIONS CHILDREN'S FUND (UNICEF). Estado mundial de la infancia 2009: salud materna y neonatal. Nova York, 2008a.

UNITED NATIONS CHILDREN'S FUND (UNICEF). Progreso para la infancia: un balance sobre la mortalidad materna. Nova York, 2008 b.

UNITED NATIONS EDUCATIONAL, SCIENTIFIC AND CULTURAL ORGANIZATION (UNESCO). Global Education Digest 2008: comparing education across the world. Montreal: Institute for Statistics, 2008. 